\title{
A novel soft sensor for measuring and controlling recovery in a high-purity, multi- component, side-draw distillation column
}

A. Udugama, Isuru; Alvarez Camps, Martina; Taube, Michael A.; Thawita, Chatchayarat; Anantpinijwatna, Amata; Mansouri, Seyed Soheil; Young, Brent R.; Yu, Wei

Published in:

Industrial \& Engineering Chemistry Research

Link to article, DOI:

10.1021/acs.iecr.9b04594

Publication date:

2019

Document Version

Peer reviewed version

Link back to DTU Orbit

Citation (APA):

A. Udugama, I., Alvarez Camps, M., Taube, M. A., Thawita, C., Anantpinijwatna, A., Mansouri, S. S., Young, B. R., \& Yu, W. (2019). A novel soft sensor for measuring and controlling recovery in a high-purity, multicomponent, side-draw distillation column. Industrial \& Engineering Chemistry Research, 58(43), 20026-20035. https://doi.org/10.1021/acs.iecr.9b04594

\section{General rights}

Copyright and moral rights for the publications made accessible in the public portal are retained by the authors and/or other copyright owners and it is a condition of accessing publications that users recognise and abide by the legal requirements associated with these rights.

- Users may download and print one copy of any publication from the public portal for the purpose of private study or research.

- You may not further distribute the material or use it for any profit-making activity or commercial gain

- You may freely distribute the URL identifying the publication in the public portal 


\section{Process Systems Engineering}

Subscriber access provided by DTU Library

\section{A novel soft sensor for measuring and controlling recovery in a high-purity, multi-component, side-draw distillation column}

Isuru A. Udugama, Martina Alvarez Camps, Michael A. Taube, Chatchayarat Thawita, Amata Anantpinijwatna, Seyed Soheil Mansouri, Brent R. Young, and Wei Yu

Ind. Eng. Chem. Res., Just Accepted Manuscript • DOI: 10.1021/acs.iecr.9b04594 • Publication Date (Web): 06 Oct 2019

Downloaded from pubs.acs.org on October 13, 2019

\section{Just Accepted}

"Just Accepted" manuscripts have been peer-reviewed and accepted for publication. They are posted online prior to technical editing, formatting for publication and author proofing. The American Chemical Society provides "Just Accepted" as a service to the research community to expedite the dissemination of scientific material as soon as possible after acceptance. "Just Accepted" manuscripts appear in full in PDF format accompanied by an HTML abstract. "Just Accepted" manuscripts have been fully peer reviewed, but should not be considered the official version of record. They are citable by the Digital Object Identifier (DOI@). "Just Accepted" is an optional service offered to authors. Therefore, the "Just Accepted" Web site may not include all articles that will be published in the journal. After a manuscript is technically edited and formatted, it will be removed from the "Just Accepted" Web site and published as an ASAP article. Note that technical editing may introduce minor changes to the manuscript text and/or graphics which could affect content, and all legal disclaimers and ethical guidelines that apply to the journal pertain. ACS cannot be held responsible for errors or consequences arising from the use of information contained in these "Just Accepted" manuscripts. 


\title{
A novel soft sensor for measuring and controlling
} recovery in a high-purity, multi-component, side-

\section{draw distillation column}

\author{
Isuru A. Udugama ${ }^{1, \dot{+}, \text { Martina Alvarez Camps }}{ }^{1, \dot{f}}$, Michael A. Taube ${ }^{2}$, Chatchayarat Thawita ${ }^{3}$, \\ Amata Anantpinijwatna ${ }^{3}$, Seyed Soheil Mansouri ${ }^{1}$, Brent R. Young, *, Wei Yu \\ IProcess and Systems Engineering Center (PROSYS), Department of Chemical and Biochemical \\ Engineering, Technical University of Denmark, Lyngby, Denmark \\ ${ }^{2} S \&$ D Consulting LLC, Houston, Texas, U.S.A \\ ${ }^{3}$ Department of Chemical Engineering, Faculty of Engineering, King Mongkut's Institute of \\ Technology Ladkrabang, Chalongkrung Rd., Ladkrabang, Thailand \\ ${ }^{4}$ Department of Chemical \& Materials Engineering, the University of Auckland, Auckland, \\ New Zealand \\ *Correspondence: b.young@auckland.ac.nz \\ $\ddagger$ Authors contributed equally
}

\begin{abstract}
KEYWORDS: High-purity distillation, multi-component, side-draw, inferential measurements, distillation control, density
\end{abstract}




\begin{abstract}
The use of soft sensors for monitoring purposes is an established practice in the process industry. In this study, the focus has been on developing a soft sensor that can be used to monitor the product recovery rate of double-ended, high-purity distillation columns with a side-draw. To this end, this study specifically focuses on developing a cost-effective and accurate soft sensor for an industrial methanol distillation unit where a side-draw is used to meet the parts per million level impurity specifications. The novel soft sensor is based on the unique characteristics of the mass balance in this type of column, and uses the density measurement at the side-draw together with the flow rates of the side-draw and product draw to calculate the product recovery rate. The developed soft sensor was validated against real plant data as well as on a process simulation of an industrial methanol distillation column. The soft sensor demonstrated the ability to predict product recovery to an accuracy of $0.05 \%$ and showed good dynamic performance. The proposed soft sensor was next used as a process variable in the development of a supervisory scheme and a model predictive control scheme, which were able to operate the process at product recovery rates of $99.5 \%$ while honoring critical product and bottoms product specifications.
\end{abstract}




\subsection{Introduction}

The control of high-purity distillation columns has been an area of active interest for close to half a century ${ }^{1}$. From the on-set one key issue that has hindered the control of high-purity distillation processes has been the difficulty in accurately inferring key variables such as composition of a distillate stream ${ }^{1}$. Since these early times the key desirable attributes for inferential measurements have been the same: these are a high signal to noise ratio, fast response and low cost - among others ${ }^{2}$. The concept of soft sensors/ inferential measurements has been based on linking first principles based models and historical data to create algorithms that can link a measurable variable with the desirable one ${ }^{2}$. The use of soft sensors in distillation is a wellestablished practice, particularly those focused on composition inference that relies on temperature measurements ${ }^{3-5}$. Bettoni et al..$^{5}$ used temperature measurements to estimate the composition of side-draw products. Their work showed that inferential control offered better performance than tray temperature control but failed to fully reject disturbances. Wang et al. ${ }^{6}$ studied the control of a dividing wall column and compared control schemes with on-line analysers, and with temperature-inferred control. In recent years work has also been carried out on using adaptive fuzzy logic concepts in developing composition estimations in reactive distillation columns ${ }^{7}$, the development of inferential controls for crude oil distillation units ${ }^{8}$, and the development of a non-linear profile observer for high-purity distillation columns ${ }^{9}$.

Similar to sensor development, the area of high-purity distillation control has been an area of active interest. In terms of control, high-purity distillation is a process with highly non-linear dynamics, that make it hard to control ${ }^{10}$. Extensive work has been carried out on of high-purity distillation with applications such as cryogenic air separation ${ }^{11}$ as well as more theory oriented works ${ }^{12,13}$. Udugama et al ${ }^{10,14-20}$ have also looked at this area of high-purity distillation columns 
extensively in the recent years, especially an industrial methanol distillation column where a multi-component product stream needs to be distilled into a high-purity product in a side-draw distillation column.

Product recovery $(\beta)$ is the ratio between the mass flow of the product to the mass flow of the product entering the column and as shown by Udugama et al. ${ }^{21}$ it is a key performance indicator of the economic performance of a distillation column. While gas chromatography sensors that monitor the concentration together with Coriolis flow meters that monitor the flow rates can be used to monitor these values, these sensors are expensive to purchase and operate, limiting their application to processes where a significant economic benefit can be realized by their introduction. Gas chromatography, for instance, requires trained technicians to provide accurate results, that make operation $70 \%$ of its overall cost ${ }^{22}$. Thus there is a need for the development of soft sensors that can perform the duty at the same level of accuracy and speed. In this work a novel density-based soft sensor for a high-purity multi-component methanol distillation column was developed and incorporated into a control structure.

This manuscript is divided into several sections. Firstly, in Section 2.0, some background on the industrial methanol distillation process is given. In Section 3.0 the development of the soft sensor is described in detail, while Section 4.0 details the development of both the decentralized and the MPC control schemes using the newly developed soft sensor. In Section 5.0 the developed controls are tested, with a traditional DV distillation control structure acting as a basis of comparison. Finally, conclusions are drawn in Section 6.0. 


\subsection{Background}

In industrial methanol distillation a methanol/water mixture with trace amounts of ethanol $(150 \mathrm{ppm})$ needs to be refined into AA grade methanol with less than $10 \mathrm{ppm}$ ethanol. In addition, the bottom water stream is required to have a methanol concentration of $<5-10 \mathrm{ppm}$ to satisfy environmental standards. In order to achieve this double ended purity target, the sidedraw is used to remove the unwanted ethanol. For profitable operations the methanol recovery needs to be maximized and is typically operated at a recovery of $98 \%$, while the re-boiler duty is kept to a minimum ${ }^{15}$. Figure 1 illustrates a typical methanol distillation column configuration. 


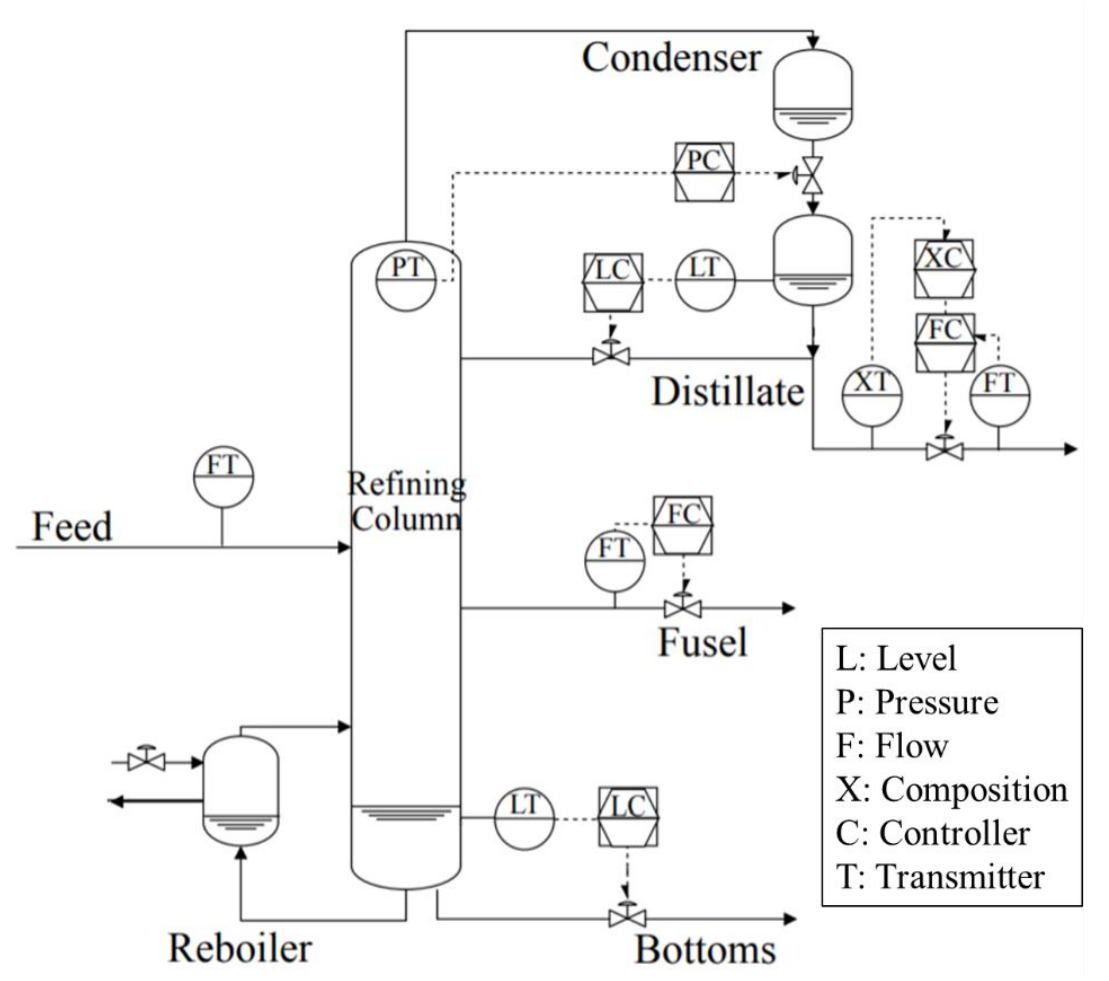

Figure 1. A schematic of a distillation column for which methanol is the top product and water is the bottom product, while ethanol is removed through the side-draw.

For the study in question, the feed of the column has been taken to be $142.5 \mathrm{t} / \mathrm{hr}$ and has a composition of methanol $(82.6 \% \mathrm{wt})$, water $(17.4 \% \mathrm{wt})$, ethanol (at a concentration of $150 \mathrm{ppm})$ and small amounts of butanol $(<100 \mathrm{ppm})$. The process aims for the recoveries and purities mentioned, which require side-draw flow rates of $3 \mathrm{t} / \mathrm{hr}$, at an ethanol concentration of $0.66 \% \mathrm{wt}$. Detailed specifications for the process can be seen in Table 1, where the mass fractions in the process simulation have been validated against real plant data. Large deviations are seen only at the ppm level, where the percentage errors are in fact very small absolute errors. 
Table 1. Mass balance specifications of the column separating methanol, water, ethanol and butanol based on industrial plant data.

\begin{tabular}{|c|c|c|c|c|c|}
\hline & & Plant data & Simulation & Units & Error (\%) \\
\hline \multirow[t]{5}{*}{ Distillate } & Flow Rate & \multicolumn{2}{|c|}{115.5} & $t / h \mathbf{r}$ & \\
\hline & Methanol & 99.99 & 99.99 & Mass Frac (\%) & 0 \\
\hline & Ethanol & 8 & 8 & ppm & 0 \\
\hline & Isobutanol & 0 & 0 & ppm & 0 \\
\hline & Water & 85 & 30 & ppm & 65 \\
\hline \multirow[t]{5}{*}{ Fusel } & Flow Rate & \multicolumn{2}{|c|}{ 3.0 } & $t / h r$ & \\
\hline & Methanol & 65 & 65 & Mass Frac $(\%)$ & 0 \\
\hline & Ethanol & 0.66 & 0.68 & Mass Frac $(\%)$ & 3 \\
\hline & Isobutanol & 47 & 59 & ppm & 26 \\
\hline & Water & 34.4 & 34.3 & Mass Frac (\%) & 0.3 \\
\hline \multirow[t]{5}{*}{ Bottoms } & Flow Rate & \multicolumn{2}{|c|}{24.0} & $\mathbf{t} / \mathbf{h r}$ & \\
\hline & Methanol & 5 & 3 & ppm & 40 \\
\hline & Ethanol & 0 & 0 & ppm & 0 \\
\hline & Isobutanol & 500 & 550 & ppm & 10 \\
\hline & Water & 99.94 & 99.94 & Mass Frac(\%) & 0 \\
\hline \multirow[t]{2}{*}{ Specifications } & Re-boiler Duty & \multicolumn{2}{|c|}{88.25} & MW & - \\
\hline & Methanol Recovery & \multicolumn{2}{|c|}{98} & $\%$ & - \\
\hline
\end{tabular}




\subsection{Design and Thermodynamics}

All simulations were carried out using VMGSim V.10 and Aspentech HYSYS V.8.8. The design inputs shown in Table 2 were used in setting up the steady state and subsequent dynamic simulations.

Table 2. Side Draw Distillation Column Design Parameters.

\begin{tabular}{|c|c|c|}
\hline Design Parameter & Specification & Units \\
\hline Condenser Pressure & 134 & $\mathrm{kPa}$ \\
\hline Bottoms Pressure & 209 & $\mathrm{kPa}$ \\
\hline Total Number of Trays & 89 & - \\
\hline Location of Side-draw & 13 & Tray number (from bottom) \\
\hline Column Diameter & 6.1 & $\mathrm{~m}$ \\
\hline
\end{tabular}

In addition, the reboiler in the simulation was set to be a once through reboiler without baffles and the reboiler duty was directly specified. The Wilson model with a Virial equation of state together with a Poynting correction was used as the property package. This model determines the activity coefficients of each component in the mixture to calculate the fugacity of the liquid. The vapour fugacity is calculated using a Virial equation of state. The simulation solver then makes the required calculations using equilibrium and enthalpy models as well as using rigorous thermodynamics. It should be noted that the default thermodynamic parameters of the process simulators were used for these property packages and settings. These values were not further adjusted as relatively good agreement between the simulation and plant data was achieved ${ }^{14}$. The column was simulated with sieve trays, and based on tray manufacturer information the overall tray efficiency of the column was set to $80 \%$, while the maximum flooding factor was set 
to $120 \%$. The flooding factor of $120 \%$ was in-line with F-factor calculations carried out by the authors in Udugama et al ${ }^{18}$. In dynamics the simulation was stabilised at operating conditions by controlling the condenser and bottoms level (tower inventory) while also controlling the column overhead pressure. The dynamic behaviour of the column was in agreement with the industrial plant data that was available to the authors, but cannot be disclosed due to confidentiality restrictions.

During traditional operation the desired $98 \%$ recovery is not directly controlled, but inferred and back-calculated daily from process reports. However, it has been shown that an improvement of recovery to $99.5 \%$ can represent a yearly profit increase of USD 3.6 million $^{21}$. As noted by Udugama et al. ${ }^{21}$ this is particularly attractive when the control installation costs are below USD 9 million. This could be achieved through the use of supervisory control layers, which are easy to understand and do not require complex software ${ }^{14}$. Cost, as mentioned, can be further reduced through the use of soft sensors which can accurately monitor and control recovery.

As it can be seen in Figure 1, a range of sensors and controllers are present on the column. Level and pressure sensors, along with the feed flow sensor are present for safety concerns, in order to ensure the distillation column is able to operate. The flowmeter in the distillation stream along with the composition sensor are required to specify the product properties necessary for the sales process; firstly, by monitoring and maintaining $<10 \mathrm{ppm}$ ethanol for AA grade methanol standards and secondly to accurately quantify the amount of methanol produced by each unit ${ }^{15}$. In the distillate stream the flow sensor corresponds to a Coriolis flow meter that must be capable of accurately quantifying the mass flow. The composition control in the distillate stream corresponds to an on-line gas chromatography sensor. For the reasons mentioned, these devices are costly to install and operate, but they are also necessary. 
Traditionally, the external mass balance of the column is used to calculate the recovery

$\beta_{\text {external }}=\frac{\dot{m}_{d, \text { meoh }}}{\dot{m}_{\text {feed,meoh }}}$

In Eq. (1) the numerator $\left(\dot{m}_{d, m e o h}\right)$ is the mass flow of methanol in the distillate stream and the denominator $\left(\dot{m}_{f e e d, m e o h}\right)$ is the methanol mass flow rate in the feed. Implementing Eq. (1) in the process gives an instantaneous reading of the recovery. Unfortunately, it does not reflect the dynamics of the process, as any changes would immediately affect the reading, thus not representing the performance of the column. It also requires an additional composition sensor on the feed stream to achieve accuracies of $+/-0.1 \%$ for a meaningful recovery value. As mentioned, this type of sensor significantly affects the capital and running costs of the scheme, so other options must be considered.

\subsection{Soft Sensor Development}

In view of the steady state mass balance of the column illustrated in Figure 1, the product recovery can be re-refined as follows:

$\beta_{\text {mass balance }}=\frac{\dot{m}_{d, \text { meoh }}}{\dot{m}_{d, \text { meoh }}+\dot{m}_{\text {side, meoh }}+\dot{m}_{\text {bottoms }, \text { meoh }}}$

Where the denominator has been re-written as the methanol leaving the column in the distillate ( $\left.\dot{m}_{d, \text { meoh }}\right)$, side-draw stream $\left(\dot{m}_{\text {side, meoh }}\right)$, and bottoms stream $\left(\dot{m}_{\text {bottoms, meoh }}\right)$. This is true because at steady state, the methanol entering the column as feed must be equal to the methanol leaving the column. Eq. (2) calculates the dynamic (or internal) state of the column and gives a good indication of the dynamic state of the recovery. 
From this starting point simplifications can be made. To begin with, it can be reasonably assumed that the amount of methanol leaving through the bottom of the column is negligible, as the bottoms methanol concentration is typically $<5$ ppm during normal operation at recoveries above $98 \%$.

With this assumption the original equation, Eq. (1), can be re-written to find the 'internal' recovery of the column $\left(\beta_{\text {internal }}\right)$ as follows:

$\beta_{\text {internal }}=\frac{\dot{m}_{d, \text { meoh, }}}{\dot{m}_{d, \text { meoh }}+\dot{m}_{\text {side, } \text { meoh }}}$

Now analyzing the process mass balance further, the overall distillate flow rate can be assumed to be equal to the methanol distillate flow rate. This can be done because the methanol makes more that $99.95 \%$ of the distillate, thus:

$\dot{m}_{d, m e o h}=\dot{m}_{d}$

This reduces Eq. (3) to:

$\beta_{\text {massflow }}=\frac{\dot{m}_{d}}{\dot{m}_{d}+\dot{m}_{\text {side, meoh }}}$

Since $\dot{m}_{d}$ is already monitored, the only remaining unknown is the side-draw methanol flow rate that can be expressed as follows:

$\dot{m}_{\text {side,meoh }}=\dot{m}_{\text {side }} \times X_{\text {meoh, side }}$

To monitor the side-draw flow rate, $\dot{m}_{\text {side }}$, a flow meter can be used while the side-draw methanol concentration, $X_{\text {side,meoh }}$, can be inferred based on a relationship between the density 
and the composition. The correlation between the density of a water/methanol mixture and the methanol mass fraction is seen in Figure 2 and Eq. (7).

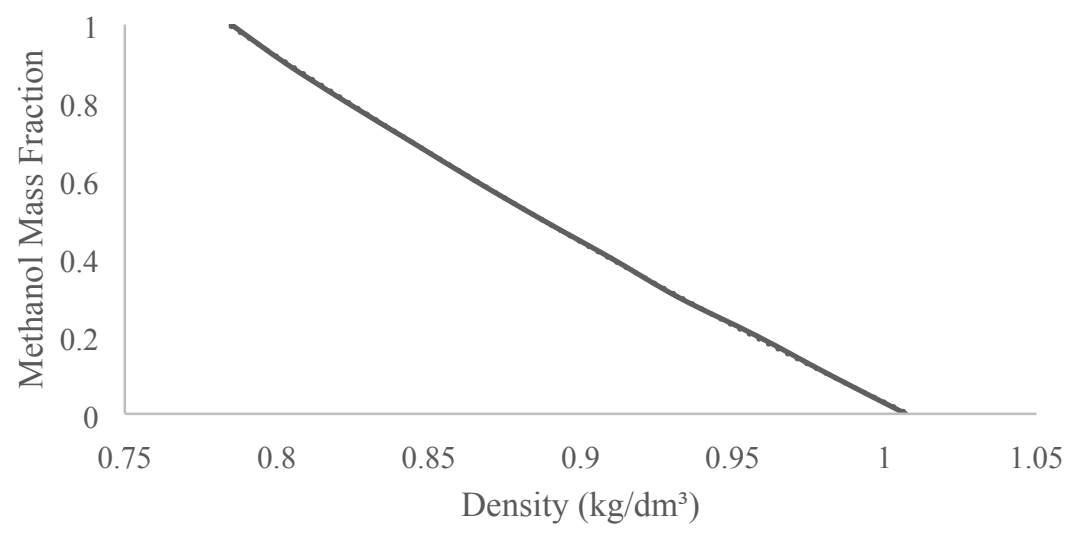

Figure 2. Relationship between composition and density at $298.15 \mathrm{~K}$ for water/methanol solutions.

$$
X_{\text {meoh } \text { side }}=3.2262 \rho_{\text {side }}{ }^{2}-10.2500 \rho_{\text {side }}+7.0533
$$

A quadratic trend line was fitted to the data to obtain a simple relationship between the parameters. It should be noted that since density changes with temperature, this relationship is only valid at $298.15 \mathrm{~K}$ which is the temperature at this regression was taken ${ }^{15}$

The side mass flow rate can then be coupled with the estimated methanol composition to calculate the methanol flow rate. The overall methanol recovery $\left(\beta_{\text {density }}\right)$ becomes:

$\beta_{\text {density }}=\frac{\dot{m}_{d}}{\dot{m}_{d}+\dot{m}_{\text {side }} X_{\text {side, } \text { meoh }}}$

Eq. (8) is to be used by the soft sensor to determine the recovery during operation. This simple concept avoids installing additional gas chromatographs to the column. The proposed soft sensor would require a Coriolis flow meter on the side-draw stream to estimate its mass flow and 
density, and would additionally use mass flow rate measurements from the already present Coriolis meter on the distillate to calculate recovery. Currently, density can be measured with Coriolis flow meters offering accuracies of $+/-0.1 \mathrm{~kg} / \mathrm{m}^{3}$, which would enable accurate calculations of the recovery rate. Although, the technology requires regular maintenance, its location on the side-draw implies a relative smaller size than required on other streams, which directly reduces the costs of the meter. Using the Coriolis meter also avoids the need for even more costly and less robust composition analyzers. Its use would thus significantly reduce complexity while still estimating recovery within acceptable accuracies.

\subsection{Soft Sensor Validation}

An analysis of the sensitivity of the density to changes in product recovery shows that for every $1 \%$ change in product recovery a corresponding density change of $\sim 70 \mathrm{~kg} / \mathrm{m}^{3}$ is expected, which in turn corresponds to a $0.05 \%$ change in product recovery change resulting in a density change of $\sim 3.5 \mathrm{~kg} / \mathrm{m}^{3}$. Considering the accuracy of density measurement device such as Coriolis flow meters (as discussed in the above paragraph), it can be concluded that these density measurement devices are capable of capturing fine changes to density which in turn allows the soft sensor to make accurate predictions.

\subsubsection{Influence of Ethanol}

During normal process operations, concentration of ethanol in the side draw reaches $0.68 \%$ (weight) and has a density value which is closer to methanol than water ${ }^{23}$. As a result of this, the density based recovery equation (Eq.8) would overestimate the amount of methanol present in the side draw. From a fundamental point of view this would result in the soft sensor to under predict the product recovery rate by $0.02 \%$. 
To further investigate this influence of ethanol, the validated process simulation was used to study the mismatch between the densities of pure methanol-water mixture and the actual side draw mixture of methanol-ethanol-water mixture (with trace butanol). Table 3 displays the results over the range of methanol concentrations that can be expected at the side draw (product recovery rates between $98 \%$ and $99.7 \%)$.

Table 3. Density mismatch between a pure methanol/water mixture and the actual side draw mixture

\begin{tabular}{|l|c|}
\hline Methanol Concentration (Wt/Wt) & Density Mismatch $\left(\mathbf{k g} / \mathbf{m}^{\mathbf{3}}\right)$ \\
\hline 0.80 & 1.1 \\
\hline 0.70 & 1.0 \\
\hline 0.60 & 1.0 \\
\hline 0.50 & 1.0 \\
\hline 0.40 & 1.0 \\
\hline 0.30 & 0.90 \\
\hline 0.20 & \\
\hline
\end{tabular}

It can be seen that on average the density mismatch is $\sim 1 \mathrm{~kg} / \mathrm{m}^{3}$, which corresponds to $\sim 0.015 \%$ mismatch in product recovery. Therefore, it can be concluded that the existence of ethanol (as well as butanol) in the side stream does not significantly affect the performance of the soft sensor. Moreover, the fact that ethanol concentrations are generally steady over a long period 
(months) and that fact that the mismatch in density is consistent over the operating range allows for an off-set to be introduced to the soft-sensor to correct for the discrepancy.

From an operational point of view, it is important to note that components such as acidic compounds as well as ketones can sometime accumulate in the side draw region as discussed by Udugama et al. in ${ }^{20}$. In these instances it is important to ensure that the accumulation of these components is at relatively low levels $(>0.25 \%$ weight at the side draw) to ensure soft sensor accuracy.

\subsubsection{Influence of Temperature}

As discussed previously, the density vs methanol regression was obtained at $298.15 \mathrm{~K}$. While in an industrial implementation the temperature of the mixture would be taken into account and then compensated for by the measurement devices ${ }^{24}$, it was decided to investigate the influence of temperature on the density measurement for robustness purposes. Table 4 shows the mismatch of density for a water/methanol mixture if the temperature of the mixture is $5 \mathrm{~K}$ higher than the standard conditions. The results shown are based on the validated process simulation. From analysing these results it can be seen that for a $5 \mathrm{~K}$ increase the soft sensor would under predict product recovery by $0.05 \%$. Thus from a practical point of view, temperature compensation must be performed relatively accurately during the field implementation of this soft sensor. 
Table 4. Density mismatch of the soft sensor for a $5 \mathrm{~K}$ increase in temperature

\begin{tabular}{|l|c|}
\hline Methanol Concentration (Wt/Wt) & Density Mismatch $\mathbf{~ k g} / \mathbf{m}^{\mathbf{3}}$ \\
\hline 0.80 & 5.0 \\
\hline 0.70 & 4.8 \\
\hline 0.60 & 4.7 \\
\hline 0.50 & 4.6 \\
\hline 0.40 & 4.4 \\
\hline 0.30 & 4.3 \\
\hline 0.20 & 4.1 \\
\hline
\end{tabular}

\subsubsection{Dynamic Validation}

To understand the dynamic behaviour of the soft sensor it was necessary to carryout step tests that compared the response of the external recovery, $\beta_{\text {external }}$ (Eq. 1), and the density recovery, $\beta_{\text {density }}$ (Eq. 8). To this end, reboiler duty step changes of $2.5 \mathrm{MW}$ were performed on the process simulation while maintaining the product ethanol concentration at 7 ppm. $\beta_{\text {internal }}$ (Eq. 3), was also plotted for the purpose of comparison. 


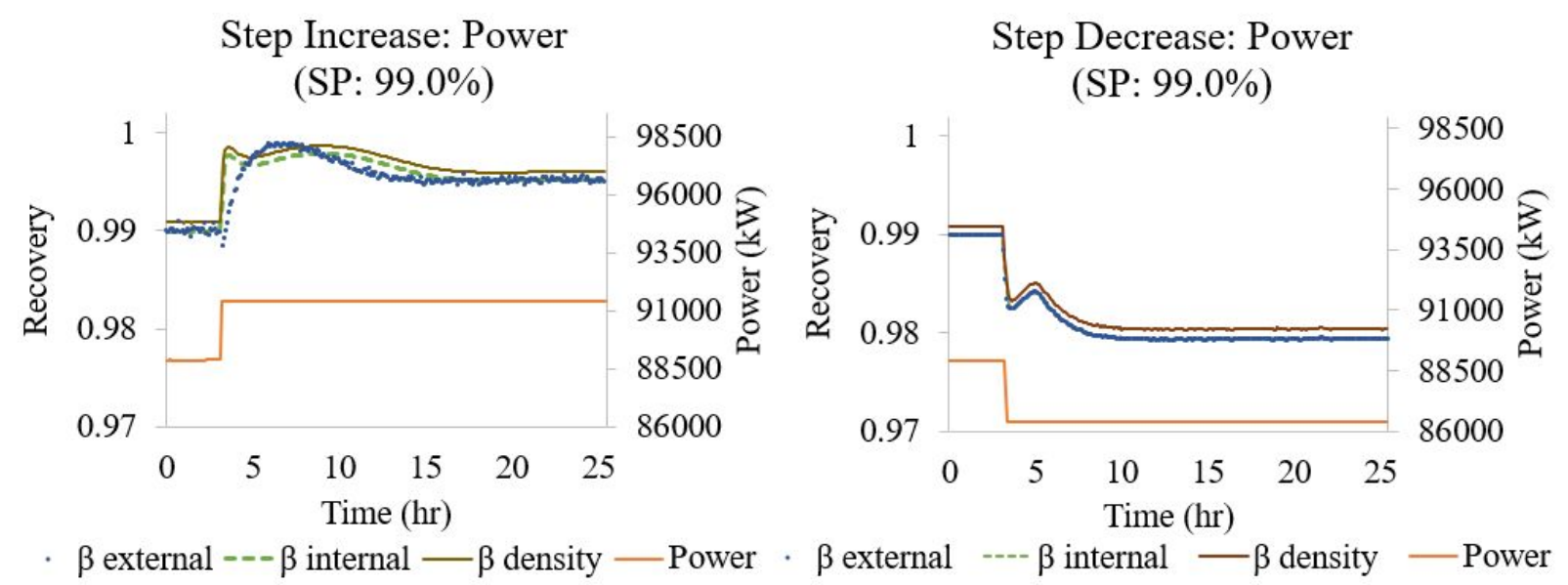

Figure 3. Step changes of re-boiler duty and its effect on recovery at $\mathrm{SP}=99.0 \%$.

Figure 3 shows that the dynamics of all three recovery calculations are similar and all three calculations take a similar time to stabilise after step tests. However, it should be noted that in the step increase, the rise time of the external recovery calculation is somewhat slower than those of the density (soft sensor) and internal recovery calculations. It can also be observed that, the density based recovery rate (soft sensor) is in general recording a recovery value that is $\sim 0.02 \%$ higher at all times. The reason for this slight mismatch was tracked back to the difference between the density vs methanol composition regression predicted by eq. 7 and by the process simulation. Further investigation into this matter revealed that the process stream where the density value was monitored in the process simulation was slightly overcooled, which resulted in this discrepancy. This mismatch was deemed to be minor hence, no further actions were taken.

\subsection{Control Schemes}

Two controller schemes, one decentralized and the other centralized, were designed in order to implement the soft sensor. The decentralized scheme is a structure based on supervisory control, so it can be implemented on a DCS and is the same as a simple DV control scheme. The 
centralized MPC scheme, on the other hand, is more advanced and requires dedicated software, but can potentially be better and is used for comparison purposes.

To qualify these systems as successful, the following criteria has been defined:

(i) Maximizing/controlling methanol recovery.

(ii) Respecting the AA grade constraint on distillate ethanol content.

(iii) Rejecting disturbances in feed.

\subsection{Supervisory Scheme}

The decentralized scheme used, was designed with the goal of providing an industrially compatible system that could meet the high-purity specifications while obtaining high recoveries and minimizing re-boiler duty. The system consists of a regulatory primary layer and a supervisory secondary layer consisting of a recovery constraint controller (RCC) and a dynamic re-boiler controller (DRC) and is based on the analysis and supervisory control structure developed by Udugama et al. ${ }^{15}$. This scheme will be referred to as Supervisory scheme.

The RCC takes the measurements of the current recovery ratio and ethanol content in the distillate stream. The controller changes the set point of the composition $\left(Y_{S P, Q C}\right)$ depending on the state of the column. In situations where the column $\beta$ is higher than the desired set point, the $Y_{S P, Q C}$ is tightened by the control structure to take advantage of the favorable recovery conditions and to bring the recovery back to set point. The aggressiveness of this reduction in set point is dictated by $M_{H}$ which was set to a value of 2 . Similarly, when $\beta$ is lower than the desired set point, $Y_{S P, Q C}$ is increased which in turn increases the recovery rate back to set point. The aggressiveness of this increase in set point is dictated by $M_{L}$ which was set to a value of 6 . 
The value of $M_{H}$ and $M_{L}$ have been set based on work carried out in Udugama et al. ${ }^{15}$ where the $M_{H}$ value was three times smaller than $M_{L}$. This means the controller responds much more aggressively to a low recovery rate situation than a high recovery rate situation. This is because a low recovery rate situation is economically undesirable, while a high recovery rate situation only needs to be managed to ensure that in the long term the mass balance of the column is kept in check. The maximum rate of change was set to $0.1 \% / \mathrm{min}$ to avoid abrupt variations in the set point. The set point is calculated as a function of recovery as follows:

$$
\begin{gathered}
Y_{S P, Q C}=Y_{S P}-M_{H} 10^{-6 \frac{\beta-\beta_{S P}}{[\%]}} \quad \text { if } \beta_{S P} \leq \beta \\
Y_{S P, Q C}=Y_{S P}-M_{L} 10^{-6 \frac{\beta-\beta_{S P}}{[\%]}} \quad \text { if } \quad \beta_{S P} \geq \beta
\end{gathered}
$$

Eq. (9) represents a high recovery scenario, while Eq. (10) represents a low recovery case. In both cases the recovery measurements are based on $\beta_{\text {density. }}$ The flow rate of the side-draw stream was set to $3113 \mathrm{~kg} / \mathrm{hr}$ in order to avoid ethanol accumulation in the column. The sidedraw flow rate value is based on industrial plant settings and is in turn set by practical limitations due to the requirement to recycle this side draw stream back to the reformer section (specifically the saturator) of a methanol production facility ${ }^{21}$. In this instance it was decided to hold this flow value constant due to the fact that varying this may affect the density based measurements.

The recovery set point, $\beta_{\text {density }}$ and feed mass flow rate are then sent to the DRC. This controller is comprised of a feed forward controller and a feedback trim controller. The feedforward controller adjusts the re-boiler duty depending on the feed flow rate, as shown in Eq. (11), while the trim controller receives information from the RCC regarding the recovery and makes small adjustments to the re-boiler. The schematic of the system is shown in Figure 4. 


$$
\frac{\dot{Q}_{R e b}}{[k W]}=0.6707 \frac{\dot{m}_{F e e d}}{[k g / h r]}-4200
$$

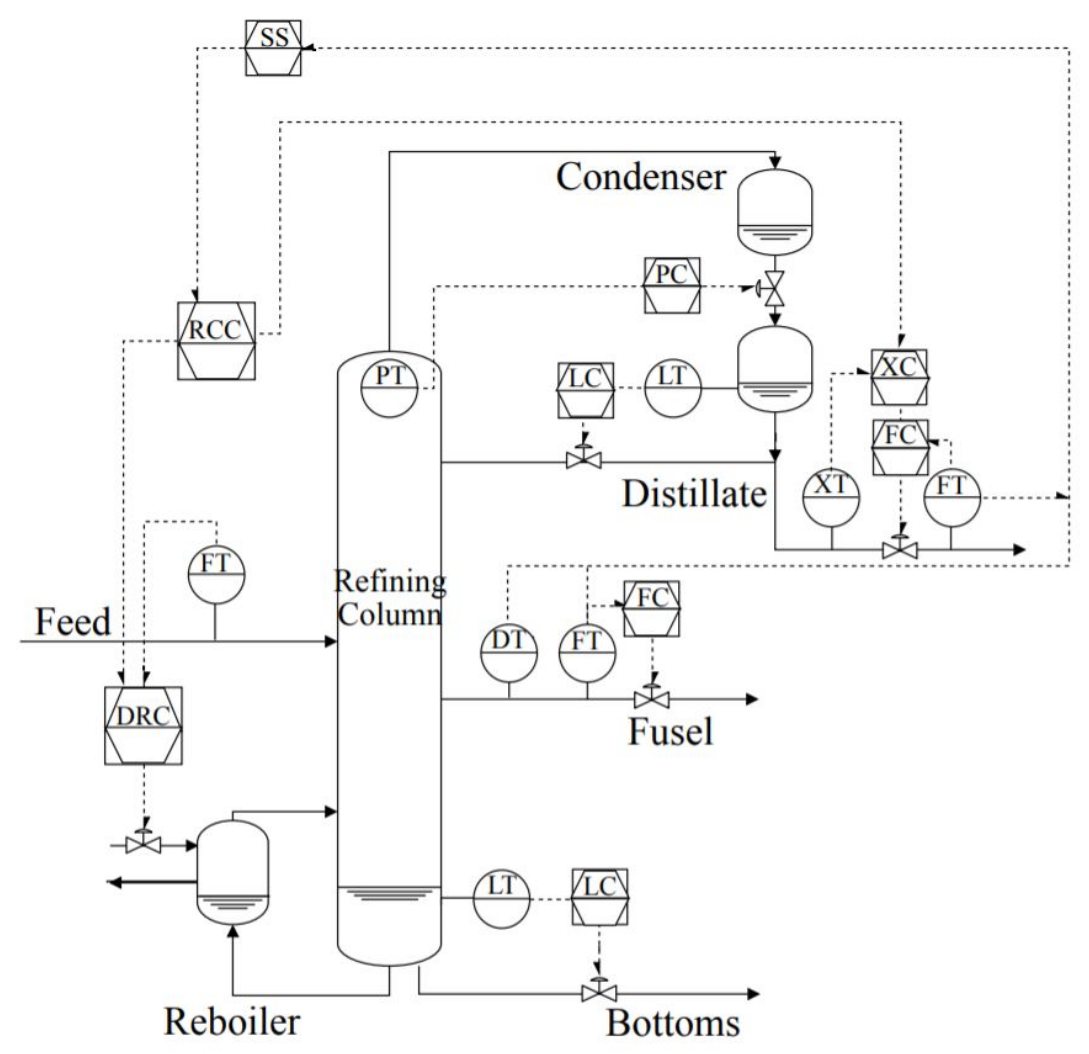

Figure 4. Supervisory control scheme, where SS stands for soft sensor.

\subsection{MPC Scheme}

A model predictive controller (MPC) scheme using a 2x2 multi-input, multi-output (MIMO) controller was designed, where each input affects both outputs. The inputs selected were the

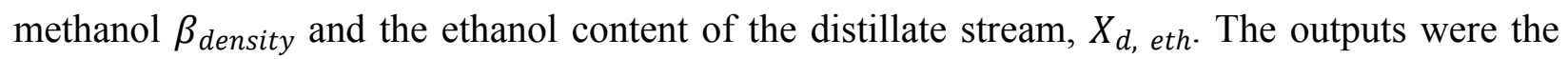
set point of the $X_{d \text {, eth }}$ controller and the re-boiler duty.

The model was built through open loop tests. The effect of re-boiler duty and distillate flow rate step changes were observed on the $\mathrm{X}_{\mathrm{d} \text {, eth }}$ and $\beta_{\text {density. }}$. The complex process dynamics observed 
through the tests, lead to the normalization of the data in order to create transfer functions that were then inserted into the MPC module as the process model. A general unconstrained MPC module available on Aspen HYSYS was used for the process simulations, but other MPC modules would also be suitable, such as unconstrained or constrained MPC controllers from Aspen PLUS (DMC or DMCplus) or MATLAB. For a constrained optimization the key variable with a hard constraint would be the ethanol composition which must be kept below 10 ppm wt. However, preliminary simulations (as confirmed in the results in Section 5.0) illustrate that at the current set point of $8 \mathrm{ppm}$ wt., this threshold is not crossed for expected process disturbances. These results indicate that adding constraints would have little benefit, while it may lower the energy savings of the MPC, through more aggressive disturbance handling. Since the authors cannot see an added benefit in introducing a constrained MPC module, which would be more time consuming to set up and maintain in an industrial setting, the general unconstrained MPC module was used. However, it is important to note, that in case there is a need to handle constraints actively, a constrained MPC must be set up as this will lead to more superior overall performance in comparison to an unconstrained MPC module. The MPC module was tuned by setting a range of parameters and variables. After a series of simulations, the sampling interval (k) was given a value of $10 \mathrm{~min}$. In a similar manner suitable values for the prediction horizon $(P)$, and the control horizon $(M)$ were found. The prediction horizon represents the number of sampling intervals into the future, while the control horizon is the number of control moves into the future that the MPC considers when predictions are made ${ }^{15}$. These parameters were set to 50 and 2 respectively. Values for the process variable and manipulated variable weighing matrices ( $\Gamma_{\mathrm{u}}$ and $\Gamma_{\mathrm{y}}$ respectively) were also required. These were found though flow rate step changes and observations on their effect on $\beta_{\text {density }}$ and $X_{d}$, eth. The observations lead to values of 0.5 for $\Gamma_{\mathrm{u}}$ 
and 1 for $\Gamma_{\mathrm{y}}$. These parameters determine the controller's ability to reject disturbances and the size of its actions. In this particular case these parameters were tuned to have a balance between not exceeding product ethanol concentration and the amount of additional reboiler duty that was used to achieve this outcome. The relatively small $\Gamma_{\mathrm{u}}$ chosen, results in larger actions and better disturbance rejection, but lower stability. Figure 5 shows the resulting scheme for the MPC.

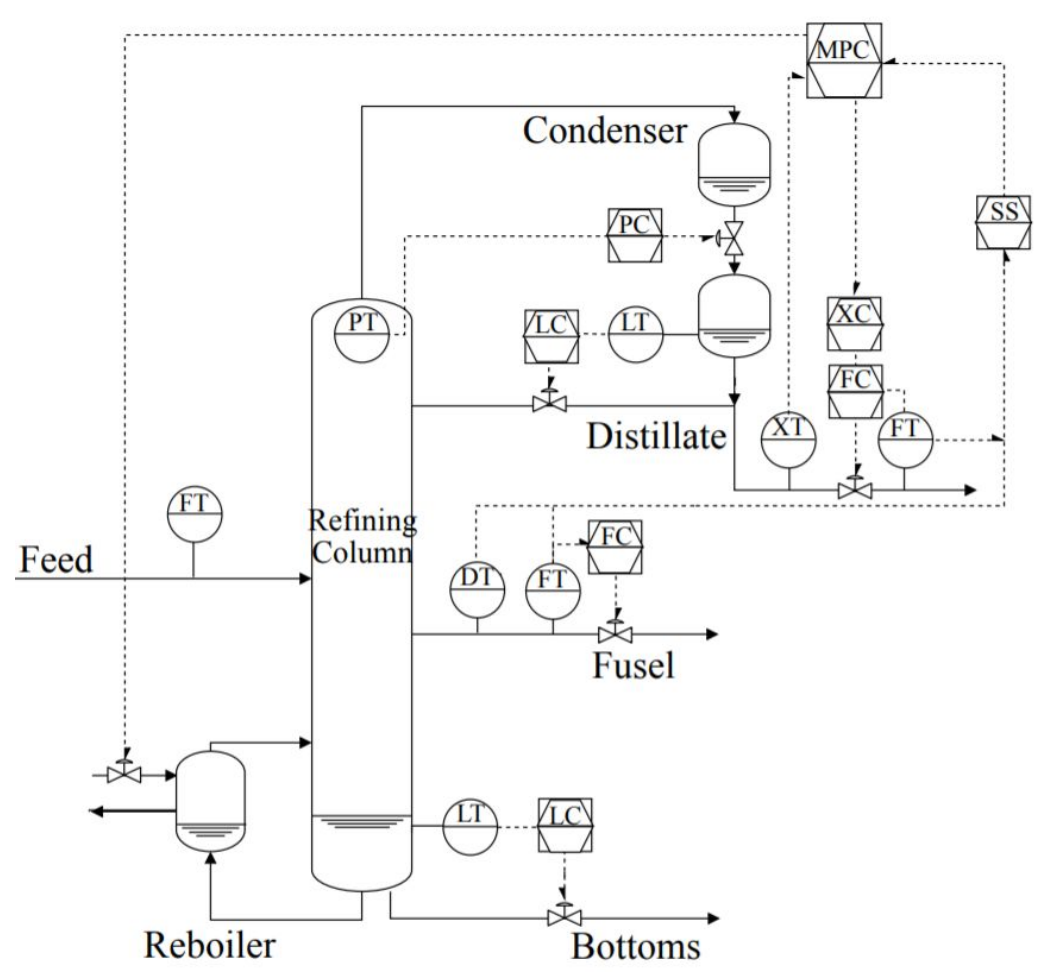

Figure 5: MPC Control Scheme.

\subsection{Disturbance testing}

A validated process model developed by Udugama et al. ${ }^{15}$ was used to implement the two control structures described in Section 4.0. In addition, a traditional DV control structure was developed where the distillate flow was used to control the product ethanol specification at 7 
ppm while the re-boiler duty was used to control the bottoms methanol concentration at $3 \mathrm{ppm}$. The product and bottoms set-point for the DV control structure were chosen to allow a sufficient operating window for the DV controller to meet product and bottoms specifications of the column, while is it also important to note that the DV controller does not control product recovery hence the recovery values seen are a result of the controller set points. Moreover, the DV controller in practice will also require a gas chromatograph to monitor the bottoms methanol composition.

\subsection{Feed Step Tests}

Flow rate step changes of $5700 \mathrm{~kg} / \mathrm{hr}(4 \%)$ were made. A change of this size is an extreme scenario, where the column suddenly takes in a large amount of liquid. The results show that the disturbance is rejected successfully by both the Supervisory and MPC schemes. As it can be seen in Figure 6, the DV and MPC schemes have large $\beta_{\text {external }}$ overshoots, while the Supervisory scheme does not change significantly. In the case of the MPC, the overshoot can be attributed to the small $\Gamma_{\mathrm{u}}$ value. The responses seen by the re-boiler duty and $X_{d, \text { eth }}$, through the MPC and Supervisory schemes are quite different. For instance, there is a required increase in re-boiler duty to overcome the increase in flow rate. In the case of the MPC this increase in duty is gradual, while the Supervisory scheme sees a more sudden change which is then reduced slightly by the feedback trim controller. The result is a steady state with lower energy requirements for the MPC, compared to the Supervisory scheme. When looking at $X_{d, \text { eth }}$ the Supervisory scheme set-up sees the decrease in recovery, and thus increases the set point of the distillate. As the 
recovery stabilizes, so does the ethanol mass fraction, although at a lower set point than before the disturbance. The MPC on the other hand, oscillates with no major overshoots.

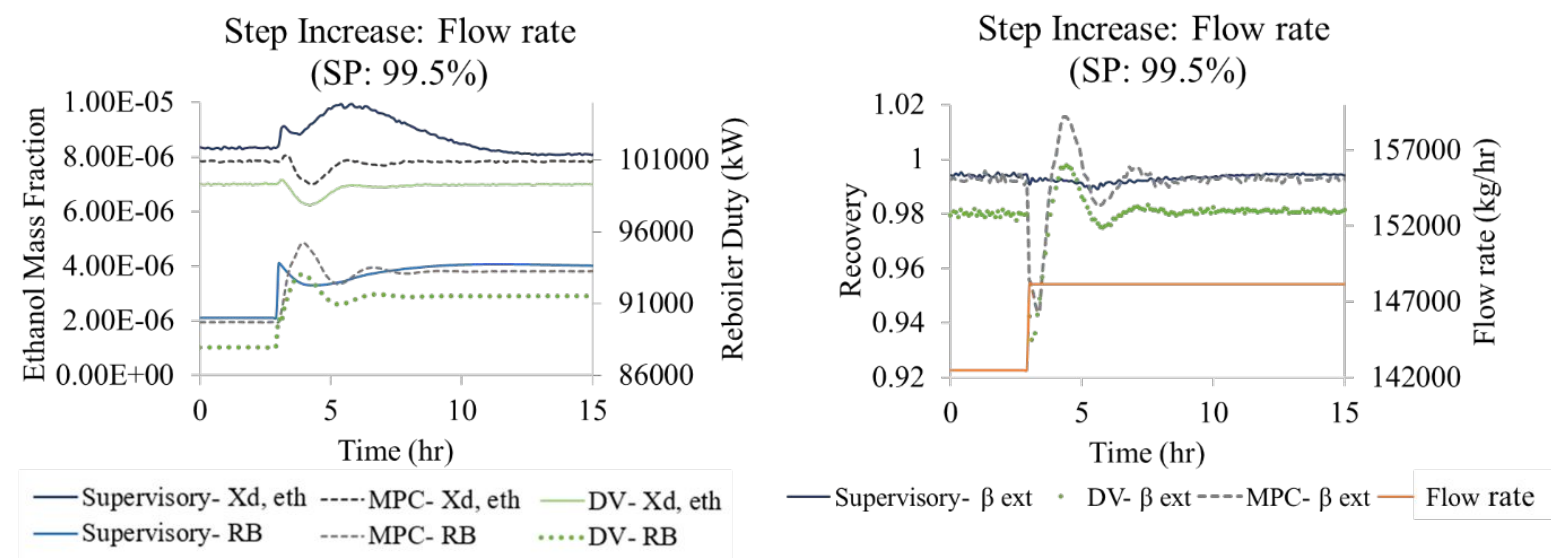

Figure 6. Flow rate step change effect on external recovery to the left, to the right its effect on ethanol mass fraction and re-boiler duty are shown.

Table 5 shows the scaled integral squared error (ISE) for the different schemes at a set point of 99.5\% using the Supervisory scheme as the basis. These values indicate that the DV and MPC schemes are able to control the $X_{d \text {, eth }}$ tightly and close to the desired set point, compared to the Supervisory scheme. On the other hand, the Supervisory scheme does a better job of controlling $\beta_{\text {external. }}$ This occurs, because as explained, the Supervisory scheme allows for the $X_{d, \text { eth }}$ to increase in order to maintain the recovery at the set point. 
Table 5. ISE of the main variables for a feed disturbance expressed as the integral squared error compared to the Supervisory scheme.

\begin{tabular}{|l|l|c|}
\hline Variable & Control Scheme & ISE (\%) \\
\hline \multirow{3}{*}{$\beta_{\text {external. }}$} & Supervisory & 100.00 \\
\cline { 2 - 3 } & MPC & 2760.78 \\
\cline { 2 - 3 } & DV & 1992.31 \\
\hline \multirow{3}{*}{$X_{d, \text { eth }}$} & Supervisory & 100.00 \\
\cline { 2 - 3 } & & \\
\cline { 2 - 3 } & & 8.24 \\
\cline { 2 - 3 } & DV & 6.94 \\
\hline
\end{tabular}

\subsection{Routine Cyclic Disturbances}

Cyclic disturbances were applied to help compare the schemes under conditions that resemble those of the 'real world'. Once more, only feed flow rate variations were performed. Sinusoidal disturbances with an amplitude of $5700 \mathrm{~kg} / \mathrm{hr}(4 \%)$ were applied at two different time periods, $t_{\text {short }}=50$ min and $t_{\text {long }}=2000$ min. Figures 7 and 8 show the effects of the flow rate changes on $\beta_{\text {external }}, X_{d, \text { eth }}$ and re-boiler duty for the three schemes. 

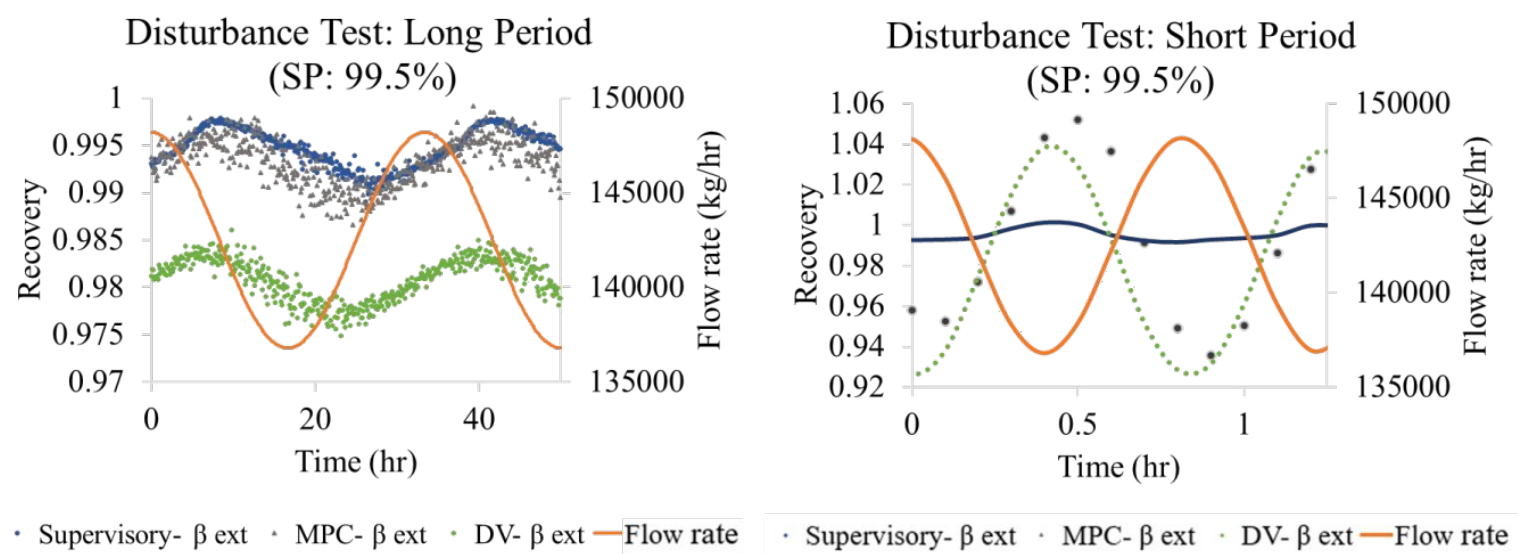

Figure 7. Cyclic changes of flow rate and its effect on external recovery for the three schemes.

The long period is shown on the left and the short period on the right.

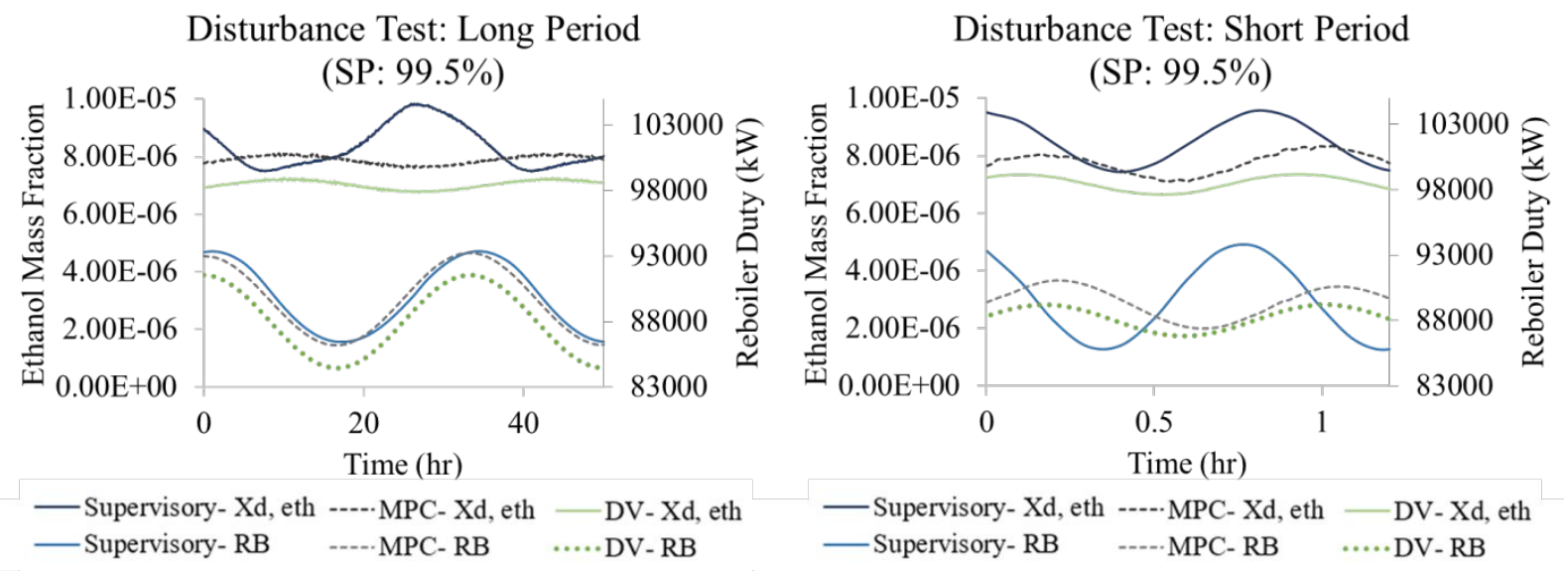

Figure 8. Cyclic changes of flow rate and its effect on ethanol concentration at the top and reboiler duty for the three schemes. The long period is shown on the left and the short period on the right.

The results also show that the $+/-0.1 \%$ accuracy requirements are met by both schemes. Larger $\beta_{\text {density }}$ measurement results were obtained throughout the different systems, though by a difference lower that $0.1 \%$. This further demonstrates that the accuracy of the soft sensor is suitable for the monitoring and control of recovery. However, since the $\beta_{\text {density }}$ measurement is 
constantly higher than $\beta_{\text {external }}$, the set point could be adjusted by less than $0.1 \%$ to obtain the desirable external recovery. This could be particularly useful for the MPC which sees lower recoveries than the Supervisory control system.

Examining the long period fluctuations, it can be seen that the response times for the recovery (6 - $9 \mathrm{hr}$ ) are similar for all three schemes. Similar response times are also seen for the re-boiler duty $(0-1.5 \mathrm{hr})$. Additionally, there are only minor differences in energy requirements $(0.2$ $0.8 \mathrm{MW}$ difference). The Supervisory scheme obtains $0.1-0.15 \%$ higher mean values for $\beta_{\text {external }}$. As explained earlier this occurs due to the controller's 'lee way' on $X_{d, \text { eth }}$, to quickly return to the specified recovery. MPC shows overall lower mean recoveries, but has tighter control on $X_{d \text {, eth }}\left(0.7 \mathrm{ppm}\right.$ lower means). For the short period fluctuations, the $\beta_{\text {external }}$ amplitudes of the DV and MPC schemes are significantly larger than those seen in the Supervisory control scheme. The response times are also different, with MPC showing a slower adjustment of the re-boiler duty ( $0.3 \mathrm{hr}$ slower than the Supervisory control). This occurs because for the MPC to react, both $\beta_{\text {density }}$ and $X_{d, \text { eth }}$ must have been affected, which for feed flow rate disturbances can take some time, as previously noted by Udugama et al. ${ }^{14}$. Tables 5 and 6 further illustrate these points by providing the quantitative comparisons. 


\subsection{Controller Performance}

Table 6 shows that for a long period disturbance, the three schemes have similar amplitudes for $\beta_{\text {external }}$ and re-boiler duty, while $X_{d, \text { eth }}$ is more tightly regulated by the MPC and DV than the Supervisory scheme. For the short period disturbance, the amplitude of the re-boiler duty and $X_{d, \text { eth }}$ are smaller for MPC and DV, while the $\beta_{\text {external }}$ amplitude is significantly smaller for the Supervisory control scheme.

The disturbance rejection ability of each scheme has also been quantified as the ratio between the disturbance of the process variable coming out and the disturbance going into the process ( $4 \%$ feed flow):

Disturbance Rejection $=\frac{\text { Disturbance amplitude } \% \text { out }}{\text { Disturbance amplitude } \% \text { in }}$

These values were then expressed as a percentage of the Supervisory scheme, as presented in Table 4. The calculation allows for a more obvious view of which scheme decreases the disturbance the most, with low values indicating a greater reduction. These results once more reinforce that the Supervisory scheme has a tighter control of the recovery, while the MPC does

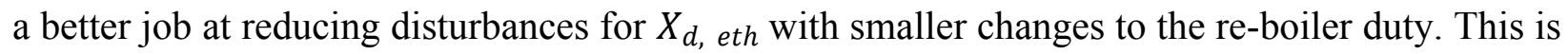
seen more significantly in the short period disturbances, since the MPC lags on acting upon changes in the recovery value. 
Table 6. Amplitude of key variables at a recovery set point of $99.5 \%$. Those values which were considered more attractive have been highlighted. The disturbance rejection has been presented using the Supervisory scheme as the basis of comparison.

\begin{tabular}{|c|c|c|c|c|c|}
\hline $\begin{array}{l}\text { Process } \\
\text { Variable }\end{array}$ & $\begin{array}{l}\text { Control } \\
\text { Scheme }\end{array}$ & Long Period & $\begin{array}{c}\text { Disturbance } \\
\text { Rejection } \\
\text { Long Period } \\
\text { (\%) }\end{array}$ & Short Period & $\begin{array}{c}\text { Disturbance } \\
\text { Rejection } \\
\text { Short Period } \\
\text { (\%) }\end{array}$ \\
\hline \multirow{3}{*}{$\begin{array}{l}\text { Amplitude } \\
\text { (\%) }\end{array}$} & Supervisory & 0.33 & $100.00 \%$ & 0.48 & $100.00 \%$ \\
\hline & MPC & 0.31 & $94.08 \%$ & 5.80 & $1209.79 \%$ \\
\hline & DV & 0.33 & $101.42 \%$ & 5.50 & $1161.24 \%$ \\
\hline \multirow{3}{*}{$\begin{array}{l}\text { Re-boiler } \\
\text { Duty } \\
\text { Amplitude } \\
\text { (MW) }\end{array}$} & Supervisory & 3.50 & $100.00 \%$ & 4.05 & $100.00 \%$ \\
\hline & MPC & 3.50 & $100.22 \%$ & 1.55 & $38.60 \%$ \\
\hline & DV & 3.50 & $102.09 \%$ & 1.20 & $30.29 \%$ \\
\hline \multirow{3}{*}{$\begin{array}{l}X_{d, \text { eth }} \\
\text { Amplitude } \\
\text { (ppm) }\end{array}$} & Supervisory & 0.75 & $100.00 \%$ & 1.03 & $100.00 \%$ \\
\hline & MPC & 0.21 & $30.35 \%$ & 0.50 & $53.99 \%$ \\
\hline & DV & 0.20 & $32.46 \%$ & 0.34 & $40.22 \%$ \\
\hline
\end{tabular}


Both the Supervisory and MPC schemes maintain the ethanol content below the $10 \mathrm{ppm}$ requirement for both long and short period disturbances. However, Table 7 shows that the MPC struggles to reach the recovery set point, and obtain recoveries over $0.1 \%$ smaller than the Supervisory scheme. This reduction in recovery, in turn results in lower energy requirements for the MPC, which are nonetheless similar to those of the Supervisory scheme in relation to the energy consumption of the DV controller. Considering the complexities of MPC systems and the small differences in mean re-boiler duties, the Supervisory scheme seems to be the more attractive scheme. The Supervisory scheme achieves the $X_{d}$, eth requirements, while obtaining higher recoveries and a tighter control over this variable. Having said this, the tighter control of MPC over the ethanol content allows for a greater buffer zone in the quality of the product. It may also be possible to improve the overall performance of the MPC with further tuning. Since both schemes succeed at regulating the parameters of interest with the use of the proposed soft sensor, the choice of scheme will ultimately rely on economic and operational decisions. It is also important to note that in both long and short period disturbances the production rate of the supervisory control scheme is slightly higher than the MPC and is somewhat higher than the DV controller 
Table 7. Average values of key variables at a recovery set point of $99.5 \%$. Those values which were considered more attractive have been highlighted.

\begin{tabular}{|c|c|c|c|}
\hline Process Variable & Control Scheme & Long Period & Short Period \\
\hline \multirow{3}{*}{ Feed Flow Rate Average $(\mathrm{kg} / \mathrm{hr})$} & Supervisory & 142550 & 142559 \\
\hline & MPC & 142509 & 142482 \\
\hline & DV & 142567 & 142504 \\
\hline \multirow{3}{*}{$\beta_{\text {external }}$ Average (\%) } & Supervisory & 99.42 & 99.48 \\
\hline & MPC & 99.27 & 99.36 \\
\hline & DV & 98.03 & 98.16 \\
\hline \multirow{3}{*}{ Re-boiler Duty Average (MW) } & Supervisory & 89.87 & 89.95 \\
\hline & MPC & 89.67 & 89.18 \\
\hline & DV & 88.03 & 87.99 \\
\hline \multirow{3}{*}{$X_{d, \text { eth }}$ Average (ppm) } & Supervisory & 8.52 & 8.53 \\
\hline & MPC & 7.86 & 7.67 \\
\hline & DV & 7.00 & 7.00 \\
\hline \multirow{2}{*}{ Product flow Rate Average $(\mathrm{kg} / \mathrm{hr})$} & Supervisory & 117063.4 & 117141.4 \\
\hline & MPC & 116853.1 & 116936.9 \\
\hline
\end{tabular}




\begin{tabular}{|l|l|l|c|}
\hline & DV & 115440.5 & 115542.5 \\
\hline
\end{tabular}

Overall the results show good accuracy and control of the recovery, in particular the Supervisory scheme. As previously discussed, this control allows for high recoveries to be achieved and in turn higher profits for the plant. The use of density to track composition and recovery thus shows great potential for the improvement of current distillation processes at a lower cost than can be achieved through traditional methods.

A similar overall controller performance can be observed when comparing the product recovery, ethanol composition and reboiler duty variations recorded in Udugama et al ${ }^{14}$ (where similar MPC and supervisory control structures were developed but with the use of direct (external) recovery calculations) to those recorded in this study. The product recovery rate and reboiler duty that is achieved using the density-based controllers can be regarded to be similar to that of using direct recovery calculations. However, it is also important to note that some of the dynamic responses of the ethanol and recovery are somewhat different. Specifically, in density-based control, the recovery amplitude during short feed flow disturbances is larger than the external recovery-based controls. This is likely due to the different underlying process dynamics and the subsequent controller tuning which is more aggressive. As a consequence the product ethanol concentration (which is directly linked to product recovery) is also different. It is also important to note that the supervisory control in this work has a static flow rate and is not changed. Secondly both MPC and the Supervisory controller are using the density based recovery measurement and have been tuned accordingly to give the best response. 


\subsection{Conclusions}

This study looks at the development and use of a density-based soft sensor to monitor and control recovery in a multi-component distillation column. To this end the study compared the traditional recovery reading against the new recovery measurement proposed, with the findings showing that the necessary accuracy of $0.05 \%$ is achieved with the operations envelope. Three different control schemes were designed on a validated industrial process simulator; (i) a decentralized scheme, (ii) an MPC scheme, and (iii) a simple decentralized DV scheme with no recovery tracking. An analysis of the three schemes shows the use of the soft sensor allows for better control of recovery while obtaining AA grade methanol. The use of this soft sensor represents a cheaper alternative to traditional recovery calculations. Its implementation in complex control systems offers a source of cost reduction for these schemes.

\section{ACKNOWLEDGMENT}

The authors would like to acknowledge the Carlsberg Foundation Grant CF17-403. 


\section{REFERENCES}

(1) Fuentes, C.; Luyben, W. L. Control of High-Purity Distillation Columns. Ind. Eng. Chem. Process Des. Dev. 1983, 22 (3), 361-366.

(2) Zook, D.; Bonne, U.; Samad, T. Sensors in Control Systems. In CONTROL SYSTEMS, ROBOTICS AND AUTOMATION-Volume XXI: Elements of Automation; 2009.

(3) Fortuna, L.; Graziani, S.; Xibilia, M. G. Soft Sensors for Product Quality Monitoring in Debutanizer Distillation Columns. Control Eng. Pract. 2005, 13.4, 499-508.

(4) Smets, I. Y. Inferring Distillation Product Composition: A Hybrid Soft Sensor Approach. IFAC Proc. Vol. 2007, 40.5, 167-172.

(5) Bettoni, A.; Bravi, M.; Chianese., A. Inferential Control of a Sidestream Distillation Column. Comput. Chem. Eng. 2000, 23.11-12, 1737-1744.

(6) Wang, J. Composition Control and Temperature Inferential Control of Dividing Wall Column Based on Model Predictive Control and PI Strategies. Chinese J. Chem. Eng. 2018, 26.5, 1087-1101.

(7) Khazraee, S. M.; Jahanmiri, A. H. Composition Estimation of Reactive Batch Distillation by Using Adaptive Neuro-Fuzzy Inference System. Chinese J. Chem. Eng. 2010, 18 (4), $703-710$.

(8) Ahmadian Behrooz, H. Robust Set-Point Optimization of Inferential Control System of Crude Oil Distillation Units. ISA Trans. 2019.

(9) Shin, J.; Seo, H.; Han, M.; Park, S. A Nonlinear Profile Observer Using Tray Temperatures for High-Purity Binary Distillation Column Control. Chem. Eng. Sci. 2000, $55(4), 807-816$.

(10) Udugama, I. A.; Munir, T.; Kirkpatrick, R.; Young, B. R.; Yu, W. High Purity, High 
Recovery, Multi-Component Methanol Distillation Control; 2015; pp 1613-1618.

(11) Chen, Z.; Henson, M. A.; Belanger, P.; Megan, L. Nonlinear Model Predictive Control of High Purity Distillation Columns for Cryogenic Air Separation. IEEE Trans. Control Syst. Technol. 2010, $18(4), 811-821$.

(12) Bachnas, A. A.; Tóth, R.; Ludlage, J. H. A.; Mesbah, A. A Review on Data-Driven Linear Parameter-Varying Modeling Approaches: A High-Purity Distillation Column Case Study. J. Process Control 2014, 24 (4), 272-285.

(13) Chou, C. T.; Bloemen, H. H. J.; Verdult, V.; van den Boom, T. T. J.; Backx, T.; Verhaegen, M. Nonlinear Identification of High Purity Distillation Columns. IFAC Proc. Vol. 2000, 33 (15), 415-420.

(14) Udugama, I. A.; Wolfenstetter, F.; Kirkpatrick, R.; Yu, W.; Young, B. R. A Comparison of a Novel Robust Decentralised Control Strategy and MPC for Industrial High Purity, High Recovery, Multicomponent Distillation. ISA Trans. 2017, 69, 222-233.

(15) Udugama, I. A.; Mansouri, S. S.; Huusom, K.; Maidl, A.; Taube, M. A.; Young, B. Cost Competitive "Soft Sensor" for Determining Product Recovery in Industrial Methanol. 2017, 23-28.

(16) A. Udugama, I.; Munir, M. T.; Kirkpatrick, R.; Young, B. R.; Yu, W. Side Draw Control Design for a High Purity Multi-Component Distillation Column. ISA Trans. 2018, 76, 167-177.

(17) Udugama, I. A.; Zander, C.; Mansouri, S. S.; Kirkpatrick, R.; Yu, W.; Young, B. R. A Novel Back-up Control Structure to Manage Non-Routine Steam Upsets in Industrial Methanol Distillation Columns. In Computer Aided Chemical Engineering; 2017; pp $1597-1602$. 
(18) Kraller, M. A.; Udugama, I. A.; Kirkpatrick, R.; Yu, W.; Young, B. R. Side Draw Optimisation of a High-Purity, Multi-Component Distillation Column. Asia-Pacific J. Chem. Eng. 2016, 11 (6), 958-972.

(19) Kroiss, D.; Udugama, I. A.; Yu, W. Feasibility of Divided Wall Column for High Purity and High Recovery Methanol Separation. In Modelling, Simulation and Identification / 854: Intelligent Systems and Control; ACTAPRESS: Calgary,AB,Canada, 2017.

(20) Udugama, I. A.; Mansouri, S. S.; Kirkpatrick, R.; Young, B.; Taube, M. A. Dangers of Component Trapping in Distillation: : An Industrial Methanol Distillation Case Study. In 2018 Moratuwa Engineering Research Conference (MERCon); IEEE, 2018; pp 49-53.

(21) Udugama, I. A.; Taube, M. A.; Mansouri, S. S.; Kirkpatrick, R.; Gernaey, K. V.; Yu, W.; Young, B. R. A Systematic Methodology for Comprehensive Economic Assessment of Process Control Structures. Ind. Eng. Chem. Res. 2018, 57 (39), 13116-13130.

(22) Handley, A.; Adlard, E. Gas Chromatographic Techniques and Applications; CRC press, 2001.

(23) Green, D.; Perry, R. Perry's Chemical Engineers' Handbook, Eighth Edition; McGrawHill: New York, 2008.

(24) O'Banion, T.; Emersons. Coriolis: The Direct Approach to Mass Flow Measurement. Chemical Engineering Progress. pp 41-46. 
Table of Content

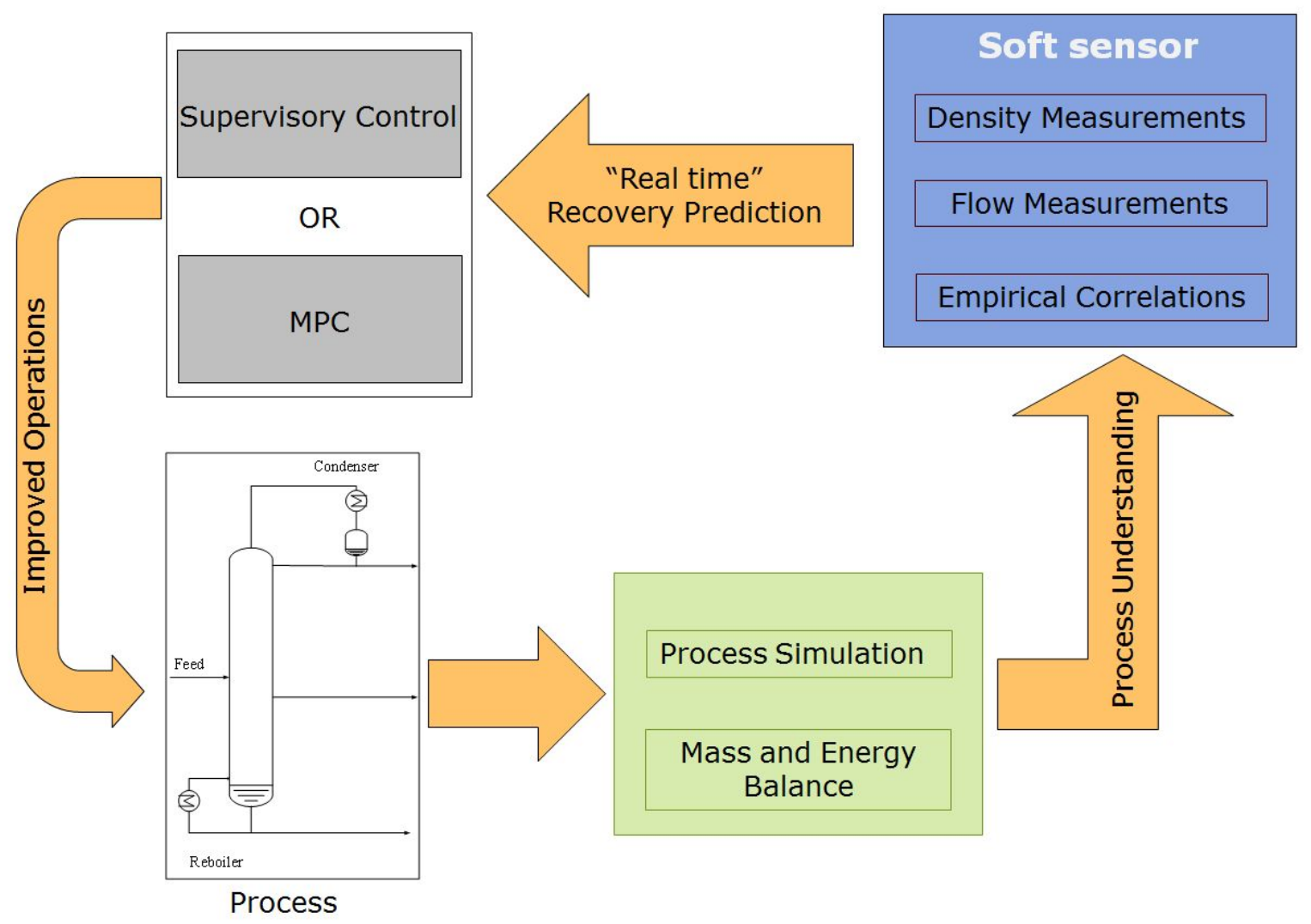

ACS Paragon Plus Environment 